\title{
PRODUTIVIDADE E QUALIDADE DE SEMENTES DE FLORES PRODUZIDAS EM SANTA MARIA
}

\author{
PRODUCTIVITY AND QUALITY OF FLOWER SEEDS \\ PRODUCED IN SANTA MARIA
}

\section{Rogério Antônio Bellé ${ }^{1}$ Rudimar Spannenberg ${ }^{2}$}

\section{RESUMO}

Com o objetivo de avaliar o potencial de produção $e$ a qualidade de sementes, foram cultivadas 15 espécies deflores nas condições de Santa Maria (Latitude 2941'S e Longitude $53^{\circ} 48^{\prime} \mathrm{W}$ ). $O$ experimento foi realizado a campo no delineamento blocos ao acaso com quatro repetições. A grande maioria das espécies produz rendimento médio de sementes elevado apesar da variabilidade. Nas condições de beneficiamento oferecidas, as espécies Dianthus, Eschscholtzia, Nigella e Fhiox produziram sementes com alta germinação. As espécies Anthirrinum, Gelosia, Gailiardia, Nicotina, Scabiosa e Zinnia possuem potencial de produção de sementes de melhor qualidade, desde que se melhore, principalmente, o beneficiamento.

Palavras-chave: rendimento, beneficiamento, germinação.

\section{SUMMARY}

The objective of this experiment was to evaluate the potential and quality of flowers seeds. Fifteen species were tested for Santa Maria (24'41'S latitude and 53'48'W longitude). The majority of the species had high seed production despite of variability. Considering the local conditions of seeds cleaning and processing the species Dianthus, Eschscholtzia, Nigella and Phlox produced seeds with high germination. The species Anthirrinum, Gelosia, Gaillardia Nicotinic, Scabbiest and Zinnia have potential to potential to produce seeds of high quality, specially, when seed cleaning and processing are improved.

Key words: yield, processing, and germination.

\section{INTRODUÇÃO}

A produção comercial de sementes de flores iniciou na segunda metade do século XIX. Nesta época as empresas mais importantes estavam na Alemanha, França, Inglaterra e, principalmente, na Holanda que se destacou na comercialização de flores associada à produção e comércio de sementes de hortaliças. Os principais centros de produção estão localizados em Erfurt e Quedlinburg na Alemanha, na região de Province na França e na região de Enkuizen na Holanda. Após a segunda guerra mundial a produção foi transferida para outros países que possuem condições climáticas também favoráveis a várias espécies, e a nova distribuição ficou assim: Alemanha, Hungria, França, Itália, USA, Holanda, Canadá, Japão, Inglaterra, Sul e Centro Africanos, além de outras áreas de importância local (VIS, 1980).0s trabalhos de produção de sementes de flores são raros, pois interessaram mais a iniciativa privada, entretanto, HAWTHORN \& POLLARD (1954) relatam para inúmeras espécies e diferentes locais, características de manejo, de rendimento e de alguns problemas culturais.

No Brasil, praticamente inexiste uma produção comercial de sementes de flores. Algumas

\footnotetext{
${ }^{1}$ Engenheiro Agrônomo, Professor Adjunto, Departamento de Fitotecnia, Universidade Federal de Santa Maria (UFSM), 97119-900, Santa Maria - RS. Autor para correspondência.

${ }^{2}$ Acadêmico do Curso de Agronomia, Bolsista de Iniciação Científica - CNPq. 
tentativas de produção foram feitas por particulares ou por empresas, que não resultaram em uma atividade duradoura que se estabelecesse como centro de produção de referência. Os países produtores exercendo um domínio do mercado internacional inibem a iniciativa nacional pelas facilidades de importação e a garantia de qualidade das sementes. Esta situação resulta na total dependência do país em sementes importadas, que segundo DONI (1989) teria as seguintes causas: falta de hábito do consumidor brasileiro, uso de cultivares não adaptados, degeneração varietal por serem híbridos ou por falta de isolamentos na produção, falta de melhoramento genético nacional, custo elevado de mão de obra para a colheita, necessidade de equipamentos de beneficiamento específicos não existentes no país e desconhecimento de métodos de produção exclusivos. Além desses, pode-se citar a falta de pesquisa na identificação de locais ou regiões favoráveis à produção, isto é, cujas condições climáticas fossem propícias ao rendimento e à qualidade das sementes produzidas.

O objetivo do presente trabalho foi de avaliar produtividade e a qualidade de sementes de 15 espécies de flores sob determinado manejo nas condições edafoclimáticas na região de Santa Maria, RS

\section{MATERIAIS E MÉTODOS}

O experimento foi conduzido a campo em área do Departamento de Fitotecnia da Universidade Federal de Santa Maria (Latitude 29 $41^{\prime} \mathrm{S}$ e longitude $53^{\circ} 48^{\prime} \mathrm{W}$ ) em solo pertencente à unidade de mapeamento São Pedro (Podzóiico Vermelho Amarelo distrófico - Paleudalf) durante o ano agrícola de 1990/91. O clima da região é subtropical e segundo a classificação de Koppen é do tipo Cfa. Os tratamentos usados foram 15 espécies de flores distribuídas segundo o delineamento blocos ao acaso com quatro repetições. As espécies botânicas estudadas com suas respectivas épocas de semeadura, data de transplante, intervalo em dias entre semeadura e transplante e espaçamentos entre plantas usados no ensaio são apresentados na tabela 1 .

As sementes utilizadas na produção, para a maioria dos cultivos, pertenciam ao cultivar chamado 'Sortida', isto é, com flores de diferentes cores, exceto paraAUhaea, Anthirrinum, Coreopsis, Eschschoüzia, e Salvia onde os cultivares eram puros para o caráter cor. A cultivar de Anthirrinum foi a "Glauca" pertencente ao grupo de porte médio. Em Rudbeckia a cultivar usada foi a "Marmelade" e em Zinnia a "Gigante da Califórnia".

As espécies de semeadura direta tiveram desbaste aos 30 dias após a emergência conservando-se um só exemplar no espaçamento indicado para o caso de Nigella, $e$ de dois para o caso de Zinnia. Devido a grande deiscência das cápsulas de Phlox, esta foi transplantada em parcelas recobertas por plástico preto. As unidades experimentais mediam $1,2 \mathrm{~m} \times 2,0 \mathrm{~m}$ perfazendo uma área de $2,4 \mathrm{~m}^{2}$. A adubação de cobertura foi realizada com potássio e nitrogênio 30 dias após a data de transplante ou semeadura nas doses de $125 \mathrm{~kg}$ de $\mathrm{K}_{2} \mathrm{O}$ por ha e de $75 \mathrm{~kg}$ de $\mathrm{N}$ por ha, seguida de incorporação. Toda a área experimental recebeu tratamento contra percevejos à base de Monocrotophós e as parcelas de Dianthus, Nigella e Zinnia receberam tratamento fúngico à base de Benomyl e Oxicloreto de Cobre. As espécies Althaea e Anthirrinum foram tutoradas.

A heterogeneidade de maturação e deiscência da grande maioria das espécies determinou que fossem realizadas inúmeras colheitas, cujos intervalos

Tabela 1 - Datas de semeaduras (DS) e transplante (DT), intervalo entre semeadura e transplante (INT), espaçamento de plantio (ESP), peneiras (PEN) e ventilação (VEN) usadas na condução, limpeza e beneficiamento de 15 espécies de flores. Santa Maria, RS.

\begin{tabular}{|c|c|c|c|c|c|c|}
\hline ESPÉCIE & DS & DT & $\begin{array}{l}\text { INT } \\
\text { (dias) }\end{array}$ & $\begin{array}{l}\text { ESP } \\
(\mathrm{cm})\end{array}$ & $\begin{array}{l}\text { PEN } \\
(\mathrm{mm})\end{array}$ & VEN \\
\hline Althaea rosea & $9 / 7 / 90$ & $29 / 9 / 90$ & 83 & $40 \times 50$ & & - \\
\hline Anthirrinum majus & $29 / 3 / 90$ & $21 / 5 / 90$ & 53 & $30 \times 30$ & $0,7 \times 0,7$ & - \\
\hline $\begin{array}{l}\text { Celosia argenta var. } \\
\text { Plumosa }\end{array}$ & $9 / 8 / 90$ & $1 / 11 / 90$ & 84 & $30 \times 40$ & - & $\mathrm{X}$ \\
\hline Coreopsis tinctotria & $9 / 8 / 90$ & $1 / 11 / 90$ & 84 & $30 \times 20$ & $2,0 \times 2,0$ & $\mathrm{X}$ \\
\hline Cosmus bipinatus & $10 / 10 / 90$ & $5 / 11 / 90$ & 27 & $40 \times 40$ & - & - \\
\hline Dianthus chinesis & $29 / 3 / 90$ & $31 / 5 / 90$ & 63 & $30 \times 20$ & $2,0 \times 2,0$ & - \\
\hline $\begin{array}{l}\text { Eschscholtzia } \\
\text { californica }\end{array}$ & $15 / 3 / 90$ & $4 / 5 / 90$ & 50 & $30 \times 15$ & - & - \\
\hline Gaillardia picta & $9 / 8 / 90$ & $12 / 10 / 90$ & 65 & $40 \times 40$ & - & - \\
\hline Nicotiana affinis & $6 / 7 / 90$ & $18 / 10 / 90$ & 104 & $60 \times 50$ & $0,7 \times 0,7$ & - \\
\hline Nigella damacena & $16 / 8 / 90$ & Direta & - & $30 \times 10$ & - & - \\
\hline Phlox dumondii & $9 / 8 / 90$ & $11 / 10 / 90$ & 64 & $20 \times 20$ & Tri24/64 & - \\
\hline Rudbeckia hirta & $9 / 8 / 90$ & $18 / 10 / 90$ & 72 & $40 \times 40$ & $0,5 \times 0,5$ & $\mathrm{X}$ \\
\hline Salvia farinacea & $20 / 7 / 90$ & $15 / 9 / 90$ & 57 & $30 \times 20$ & - & - \\
\hline $\begin{array}{l}\text { Scabiosa atropurpu- } \\
\text { rea }\end{array}$ & $29 / 3 / 90$ & $21 / 5 / 90$ & 53 & $30 \times 30$ & $2,0 \times 2,0$ & - \\
\hline Zinnia elegans & $29 / 11 / 90$ & Direta & - & $30 \times 25$ & Tri24/64 & $\mathrm{X}$ \\
\hline
\end{tabular}


variaram de dois a 40 dias dependendo da espécie e da época do ano. O momento de colheita foi determinado pela presença de um número apreciável de frutos secos que resultasse numa quantidade de sementes suficiente para as análises.

A complementação da secagem deu-se ao sol ou em câmara seca $\left(15^{\circ} \mathrm{C}\right.$ e $40 \%$ de UR) a trilha, a limpeza e beneficiamento foram realizados para cada espécie de acordo com a Tabela 1.

\section{RESULTADOS E DISCUSSÃO}

Os resultados de rendimento médio por hectare, porcentagem de plântulas normais, número de colheitas, período de colheita e coeficientes de variação estão apresentados na Tabela 2.

Althaea rosea: As cinco colheitas deramse em intervalos de $10,15,15$ e 39 dias entre si. O rendimento foi de $1.062,7 \mathrm{~kg} / \mathrm{ha}$, que ao ser comparado com aqueles informados por HAWTHORN \& POLLARD (1954), obtidos na Califórnia, observa-se que são elevados. Entretanto, as sementes possuíam baixa germinação $(42 \%$,$) com$ grande variabilidade entre as colheitas, sendo a mais tardia a de pior germinabilidade. A principal causa dessa situação foi o grande número de sementes vazias, $45 \%$ em média, e cuja eliminação das amostras não foi possível com os equipamentos disponíveis.
Anthirrinum majus: As colheitas para a maioria das inflorescências foram realizadas em duas etapas: a primeira pelas cápsulas da metade basal e a segunda pelas da parte apical, este procedimento era devido a heterogeneidade da maturação. Após a limpeza e beneficiamento das sementes obteve-se $172,2 \mathrm{~kg} / \mathrm{ha}$ de sementes ficando o rendimento dentro da variação obtida nos USA de 61 a 474kg/ha (HAWTHORN \& POLLARD, 1954), e bem superior ao informado por DONI (1989) que atribui rendimento para esta espécie de apenas $50 \mathrm{~kg} / \mathrm{ha}$. Os resultados de germinação mostram $70 \%$ de plântulas normais com pouca variação entre as colheitas, trata-se de um bom resultado, considerando-se as reduzidas dimensões das sementes; um beneficiamento mais esmerado pode melhorar a germinabilidade das sementes.

Celosia argenta var. plumosa - As colheitas foram realizadas em intervalos de 10 a 24 dias. O quatro primeiro foi efetuado por batimentos das inflorescências no interior de uma bandeja, enquanto que a última por corte total das mesmas. $\mathrm{O}$ rendimento médio obtido foi de $1.580,8 \mathrm{~kg} / \mathrm{ha}$ de sementes limpas. A média de germinação obtida foi de $72 \%$ de plântulas normais com uma grande variação entre as colheitas (36 a $95 \%$ ), e cuja causa foi a presença de sementes chochas do interior das amostras, estas variaram entre 2 e 53\%. Este fato se deve à elevada deiscência dos pixídios, mesmo imaturos, associado a intensidades

Tabela 2 - Média de rendimentos, número de colheitas, datas do período de colheita, plântulas normais e coeficientes de variação (CV) de 15 espécies de flores, Santa Maria, 1990/91.

\begin{tabular}{|c|c|c|c|c|c|c|c|}
\hline ESPÉCIE & $\begin{array}{c}\text { Rendimento } \\
(\mathrm{kg} / \mathrm{ha})\end{array}$ & $\mathrm{C} V(\%)$ & $\begin{array}{c}\mathrm{N}^{\circ} \text { de } \\
\text { colheitas }\end{array}$ & $\begin{array}{c}\text { Período de } \\
\text { Colheita }\end{array}$ & $\begin{array}{c}\text { Plântulas } \\
\text { Normais } \\
(\%)\end{array}$ & $\begin{array}{l}\text { C V } \\
(\%)\end{array}$ & $\begin{array}{c}\text { Altura } \\
\text { Planta } \\
(\mathrm{cm})\end{array}$ \\
\hline Althaea rosea & $1.062,7$ & 19,7 & 5 & $24 / 01$ a $12 / 04$ & 42 & 45,3 & 130,0 \\
\hline Anthirrinum majus & 172,2 & 21,1 & 3 & $11 / 11$ a $06 / 12$ & 70 & 9,7 & 79,5 \\
\hline Celosia argenta var. Plumosa & $1.580,8$ & 20,0 & 5 & $13 / 12$ a $01 / 03$ & 72 & 31,0 & 65,0 \\
\hline Coreopsis tinctotria & $1.295,8$ & 53,4 & 1 & $31 / 01$ & 59 & 19,3 & 90,5 \\
\hline Cosmus bipinatus & 253,4 & 29,3 & 12 & $27 / 12$ a $21 / 02$ & 40 & 28,9 & 92,0 \\
\hline Dianthus chinesis & 586,4 & 16,2 & 6 & $14 / 11$ a $27 / 03$ & 89 & 5,0 & 25,0 \\
\hline Eschscholtzia californica & 15,8 & 25,4 & 3 & $07 / 12$ a $28 / 12$ & 88 & 6,4 & $*$ \\
\hline Gaillardia picta & $2.401,8$ & 22,5 & 11 & $18 / 01$ a $16 / 05$ & 60 & 12,4 & $*$ \\
\hline Nicotiana affinis & 608,8 & 61,3 & 6 & $17 / 12$ a $04 / 03$ & 73 & 20,4 & 77,0 \\
\hline Nigella damacena & 206,5 & 70,2 & 4 & 09/01 a 29/01 & 81 & 8,3 & 31,5 \\
\hline Phlox dumondii & 743,0 & 13,1 & 23 & $17 / 12$ a $29 / 04$ & 96 & 3,3 & $*$ \\
\hline Rudbeckia hirta & 428,9 & 31,6 & 4 & $19 / 02$ a $19 / 03$ & 64 & 17,5 & 47,0 \\
\hline Salvia farinacea & 16,0 & 71,9 & 5 & $19 / 11$ a $21 / 01$ & 23 & 55,4 & $*$ \\
\hline Scabiosa atropurpurea & $2.625,2$ & 10,6 & 13 & $14 / 11$ a $14 / 03$ & 68 & 25,2 & 89,0 \\
\hline Zinnia elegans & 500,0 & 4,3 & 8 & $25 / 02$ a $19 / 04$ & 73 & 20,0 & 82,0 \\
\hline
\end{tabular}


diversas de batimentos das inflorescências e ao beneficiamento ineficiente das sementes para remoção do material chocho.

Coreopsis tintoctria - A época e o manejo proporcionaram um grande desenvolvimento de ramificações (12,2 ramos/planta), o que resultou em maior heterogeneidade de maturação. A colheita foi executada de uma única vez pelo corte total das plantas. A opção por este procedimento de colheita deveu-se a dificuldade de colheita de capítulo a capítulo pelas suas reduzidas dimensões. Após a secagem, trilha e limpeza grosseira resultou em $1.295,8 \mathrm{~kg} / \mathrm{ha}$. A impossibilidade de realizar-se o beneficiamento adequado com os equipamentos disponíveis efetuou-se uma análise de pureza das quatro repetições em amostras, em 4,0g, obtendo-se o valor médio de $53,6 \%$, ou $697 \mathrm{~kg} / \mathrm{ha}$ de sementes puras. A germinação média destas resultou em 59\% de plântulas normais, resultado este baixo, provavelmente devido à dormência das sementes, pois as REGRAS DE ANÁLISE DE SEMENTES (1978) não fazem recomendação de tratamento para esta espécie.

Cosmos bipinatus - A grande deiscência dos capítulos determinaram grande número de colheitas. As sementes eram colhidas desde que apresentassem a cor marrom mesmo com o capítulo fechado. O rendimento médio de sementes foi de $253 \mathrm{~kg} / \mathrm{ha}$ e uma grande variação entre as repetições $(\mathrm{CV}=29,3 \%)$ devido à morte de plantas ou a quebra de ramificações ocasionada por ventos. Mesmo assim, este dado encontra-se entre as variações relatadas por HAWTHORN \& POLLARD (1954) para os USA cujos rendimentos variaram de 110 a $388 \mathrm{~kg} / \mathrm{ha}$. A pequena quantidade de sementes obtida em cada colheita forçou a misturá-las, efetuando-se um único teste de germinação por repetição (4 x 100 sementes), e que resultou em apenas $40 \%$ de plântulas normais, mesmo assim com grande variabilidade $(\mathrm{CV}=28,9 \%)$. A baixa germinação pode ser explicada pela heterogeneidade no enchimento dos aquênios no campo, resultando muitas sementes chochas, que no momento do beneficiamento não foram descartados devido à dificuldade de diferenciação entre estas e as cheias.

Dianthus chinensis - Após as cinco colheitas de cápsulas secas, todas as plantas foram cortadas à dois centímetros do solo. O rebrote proporcionou ainda uma colheita, em 27/03, que contribuiu com $17 \%$ do rendimento total de $586,4 \mathrm{~kg} / \mathrm{ha}$ de sementes, mesmo com a redução de $22 \%$ no número de plantas. Este resultado é bem superior ao obtido na Inglaterra com $386,4 \mathrm{~kg} / \mathrm{ha}$ (HAWTHORN \& POLLARD, 1954). No beneficiamento, o simples peneiramento das cápsulas bem secas produz sementes muito limpas, ao serem esmagadas recuperar-se 20 à $50 \%$ de sementes, mas com pureza inferior pois inúmeros resíduos de cápsulas são de difícil remoção. O resultado de germinação foi alto, $89 \%$ de plântulas normais, e com grande homogeneidade entre as repetições.

Eschscholtzia californica - As colheitas realizadas renderam somente o equivalente a $15,8 \mathrm{~kg} / \mathrm{ha}$, pelas seguintes razões: uso de um espaçamento pequeno ocasionou uma excessiva competição entre plantas; o surgimento de doenças e a alta deiscência de cápsulas, o que ocasionou muitas perdas. Entretanto, as sementes obtidas tiveram uma germinação elevada com $88 \%$ de plântulas normais.

Gailiardia picta - Trata-se de uma espécie de longo período de floração, vindo mesmo algumas plantas a serem bianuais. Assim, foram realizadas 11 colheitas entre $18 / 1$ e $16 / 5$ o que produziu o equivalente a $2.401,8 \mathrm{~kg} / \mathrm{ha}$ de sementes, rendimento este muito elevado. Entretanto, a germinação média resultou em $60 \%$ de plântulas normais valor este justificado pelo fato das sementes não sofrerem qualquer tipo de classificação para eliminação de aquênios chochos. Somente os vazios, facilmente visualizados, foram eliminados na trilha manual.

Nicotiana affinis - As cápsulas foram colhidas secas e a trilha efetuada por esmagamento. Após a limpeza das sementes o rendimento foi avaliado em $608,8 \mathrm{~kg} / \mathrm{ha}$ com uma grande variabilidade entre as repetições $(\mathrm{CV}=61,3 \%)$ ocasionada pela morte de plantas na parcelas. A germinação obtida foi de $73 \%$ de plântulas normais, a melhoria deste resultado não foi possível pelo precário beneficiamento e pela dormência residual das sementes.

Nigella damacena - Espécie de grande precocidade, onde todas as colheitas foram realizadas num espaço de três semanas. O rendimento foi o equivalente a $206,5 \mathrm{~kg} / \mathrm{ha}$ de sementes, este poderia ser maior se não fosse a morte de plantas por doenças, o que originou a grande variabilidade entre as repetições $(\mathrm{CV}=$ $70,2 \%$ ). Já a germinação foi de $90 \%$ de plântulas normais; este excelente resultado deve-se a melhor classificação das sementes, pois são sementes pouco maiores, e por ser realizada a quebra adequada da dormência.

Phlox drumondii - A alta deiscência das cápsulas necessitou que fossem realizadas colheitas muito freqüentes, de um total de 23, 18 delas foram de cápsulas secas sobre as plantas e cinco sob o plástico preto que servia de cobertura, com o auxilio de um aspirador de pó. O rendimento total foi de $743 \mathrm{~kg} / \mathrm{ha}$ e muito superior aos obtidos na Holanda cujos valores ficaram entre 167 e $222 \mathrm{~kg} / \mathrm{ha}$ (HAWTHORN \& 
POLLARD, 1954). A porção recuperada pela aspiração representou $67,7 \%$ do total. A germinação média das sementes foi muito elevada, $96 \%$, e o modo de colheita não influenciou a qualidade germinativa das mesmas.

Rudbeckia hirta - Os capítulos colhidos, após secos, foram trilhados em moinho escarificador. Após a limpeza a avaliação do rendimento resultou em $428,9 \mathrm{~kg} / \mathrm{ha}$ de sementes com uma germinação média de $64 \%$ de plântulas normal resultado este baixo pela não eliminação suficiente de aquênios vazio observação esta confirmada no teste de germinação onde, em media, $31 \%$ deles assim se apresentavam.

Solvia farinacea - Planta vivaz, introduzida em Santa Maria em 1987, e normalmente cultivada como anual. Seu comportamento como planta ornamental é altamente satisfatório pela abundante e duradoura floração. No entanto, a produção de sementes foi mínima, apenas o equivalente a $16 \mathrm{~kg} / \mathrm{ha}$ com germinação muito baixa $23 \%$, pois a maioria das sementes apresentavam-se sem embrião ou algumas não germinaram por problemas de dormência. Este resultado mostra, que existe ainda, problemas de adaptabilidade da espécie ao local.

Scabiosa atropurpurea - As muitas colheitas realizadas totalizaram um rendimento muito elevado, o equivalente à $2.625,2 \mathrm{~kg} / \mathrm{ha} \mathrm{com}$ uma grande estabilidade no rendimento, demonstrado pela pouca variação entre as repetições. As sementes limpas e beneficiadas produziram uma germinação média de $68 \%$ de plântulas normais com uma grande variabilidade entre as diferentes colheitas. Ao examinar-se os valores individuais de germinação se observa que até a quinta colheita $(6 / 12)$ as sementes obtiveram valores de germinação superiores à $82 \%$, e que a partir desta data as sementes sofreram um importante decréscimo de qualidade pelo aumento do número de sementes chochas ou vazias, e que não puderam ser retiradas pelo beneficiamento.

Zinnia elegans - As oito colheitas foram realizadas num período aproximado de dois meses. $\mathrm{O}$ rendimento obtido foi o equivalente à $500 \mathrm{~kg} / \mathrm{ha}$ de sementes com grande estabilidade de produção demonstrada pela pequena variabilidade entre as repetições $(\mathrm{CV}=4,5 \%)$. Este resultado de rendimento é bem superior aos indicados para os USA onde observou-se valores de 167 à $330 \mathrm{~kg} / \mathrm{ha}$ (HAWTHORN \& POLLARD, 1954). As sementes ao serem analisadas apresentaram um valor médio de $73 \%$ de plântulas normais com uma variabilidade de $20 \%$ entre as diferentes colheitas, demonstrando a dificuldade de reproduzir-se um benefíciamento homogéneo, além de apresentar uma dormência residual, constatada no final do teste, por uma variação entre as colheitas foi de 8 à $23 \%$ de sementes firmes.
Nas espécies estudadas não foi utilizado nenhum cultivar híbrido na multiplicação das sementes. Mas, cabe aqui salientar, para os riscos da degenerescência genética do mesmo ao longo das gerações. Mesmo entre os não híbridos o mesmo pode ocorrer por falta de isolamentos adequados entre campos de diferentes cultivares. Soma-se a isto, a falta de adaptação de vários cultivares ou espécies por serem de origem exótica. Os aspectos sanitários também são importantes, pois muitas doenças causadas, principalmente, por vírus, são transmitidas pelas sementes que acumulando-se ao longo das gerações, degeneram a cultivar. Portanto, cuidados especiais devem ser tomados na proteção e multiplicação de cultivares, pois não existe no país empresa pública ou privada, comprometida com um sistema de produção, capaz de fornecer sementes com garantias de qualidade genética e ou sanitária, para renovar o material em cultivo. A produção de sementes de flores é uma atividade altamente especializada, carente em tecnologia específica e de uma lei de proteção a cultivares, para que o melhoramento e a produção possam se desenvolver no Brasil.

\section{CONCLUSÕES}

A grande maioria das espécies de flores testadas produzem altos rendimentos de sementes, apesar da aparente instabilidade da produção; nas condições de produção e benefíciamento oferecidas somente Dianthus, Eschscoltzia. Nigella e Phiox possuem um grande potencial para produção de sementes de qualidade. $\mathrm{O}$ benefíciamento deficiente foi a principal causa da não produção de sementes de melhor qualidade em: Anthirrinum, Gelosia, Gailiardia, Nicotíana, Sacabiosa e Zinnia.

\section{REFERÊNCIAS BIBLIOGRÁFICAS}

BRASIL, Ministério da Agricultura. Departamento Nacional de Produção Vegetal Regras para Análise de Sementes. Brasília. Ministério da Agricultura, 1980, 188 p.

DONI, M.E. Produção de Sementes de Flores no Brasil: um problema a ser resolvido. Boletim Informativo da Sociedade Brasileira de Floricultura e Plantas Ornamentais, Campinas, SBFPO, São Paulo, n" 2, p. 5-6, 1989.

HAWTHORN, L.R., POLLARD, L.H. Vegetable and Flower Seed Production. New York: Blokiston, 1954. 626 p. cap. 17 Growing the Annual Flower Seeds. p. 491-522.

VIS, C. Flower Seed Production, Seed Scienee and Technology. Proceedings of the International Seed Testing Association, Genebra, v. 8, p. 495-503, 1980. 